\title{
Membrane chromatography for rapid purification of recombinant antithrombin III and monoclonal antibodies from cell culture supernatant
}

\author{
D. Lütkemeyer*, M. Bretschneider, H. Büntemeyer and J. Lehmann \\ Institute for Cell Culture Technology, University of Bielefeld, P.O. Box. 100131, W-4800 Bielefeld 1 (Germany)
}

\begin{abstract}
The task of purifying monoclonal antibodies (MAbs) and human recombinant antithrombin III (rATIII) from cell culture supernatant was carried out using two different approaches, both based on the use of membraneous matrices. The first approach employed a strongly acidic and a strongly basic membrane ion exchanger, which were evaluated for their ability to purify monoclonal antibodies and the human active recombinant antithrombin III from cell culture supernatant. Within minutes gram amounts of product could be purified in a high-flux system, specially developed for this purpose, achieving purities of $80 \%$ for MAbs and 75\% for rATIII, respectively. The capacity of the acidic membrane ion exchanger for MAbs was found to be $1 \mathrm{mg} / \mathrm{cm}^{2}$ with recoveries up to $96 \%$ and that of the basic membrane ion exchanger for rATIII was $0.15 \mathrm{mg} / \mathrm{cm}^{2}$ with recoveries up to $91 \%$. The second approach consisted of using heparin, a mucopolysaccharide with a strong affinity towards ATIII, coupled to amine-modified or epoxy-activated membranes by reductive amination, for the purification of rATIII. The ATIII binding capacities of the membranes were found to be $91 \mu \mathrm{g} / \mathrm{cm}^{2}$ for the amine-modified and $39 \mu \mathrm{g} / \mathrm{cm}^{2}$ for the epoxy-activated membrane, achieving purities of $75 \%$. The coupling proved to be fairly stable over a period of 5 months and the membranes remained operable even after steam sterilization and treatment with sodium dodecyl sulphate. Final purification in both instances was carried out by gel filtration.
\end{abstract}

\section{INTRODUCTION}

Ion-exchange and affinity chromatography are common techniques for the purification and preparation of proteins, peptides and enzymes. However, using classical soft gels or porous particle media as a matrix results in a limitation arising from the restriction of mass transport in these diffusion-dominated systems [1,2]. A different approach is the attachment of functional groups to the inner surfaces of synthetic microporous membranes (Table I). The main advantage of using membranes as a matrix is that the mass transport is convective and therefore avoids the aforementioned limitation of classical matrices $[1,2]$. Other interesting features in addi-

\footnotetext{
* Corresponding author.
}

tion to the high flow-rate include high adsorption rates and binding velocities, no problems arising from channelling, bed shift or bed collapse and the ease of scale-up and the comfort of using a prepacked stabilized matrix. Kroner and coworkers $[1,2]$ showed the purification of monoclonal antibodies (MAbs) using protein $A / G$ and acidic membrane ion exchangers on an analytical scale (single sheets of 13.4 and $42 \mathrm{~cm}^{2}$ ), using the same type of membranes that are discussed in this investigation. The isolation of microbial enzymes with affinity membranes was described by Champluvier et al. [3], Briefs and Kula [4] and Kroner et al. [5].

The aim of this work was to test new prototypes of membrane ion exchangers and heparin affinity membranes. Analytical-scale purification was carrried out using a $100 \mathrm{~cm}^{2}$ membrane in a fast protein liquid chromato- 


\begin{tabular}{|c|c|c|c|c|}
\hline & $\begin{array}{l}\text { syringe } \\
\text { top }\end{array}$ & $\begin{array}{c}\text { filter } \\
\text { holder }\end{array}$ & $\begin{array}{l}\text { membrane } \\
\text { module }\end{array}$ & $\begin{array}{l}\text { pleated } \\
\text { module }\end{array}$ \\
\hline $\begin{array}{l}\text { Area: } \\
\left(\mathrm{cm}^{2}\right)\end{array}$ & 5.4 & 12.56 & 100 & 1400,2400 \\
\hline $\begin{array}{l}\text { Flow-rate: } \\
(\mathrm{ml} / \mathrm{min})\end{array}$ & $\begin{array}{l}6 \\
*\end{array}$ & $\begin{array}{l}10 \\
*\end{array}$ & $\begin{array}{l}30 \\
\star\end{array}$ & $\begin{array}{c}850 \\
\star \star\end{array}$ \\
\hline
\end{tabular}

* FPLC, ** High flux system

Fig. 1. Schematic diagrams of the different housings containing the membranes. The syringe top and the membrane holder were equipped with single membrane sheets. The $100-\mathrm{cm}^{2}$ unit consisted of a stack of five membrane sheets. These three units were used with an FPLC or LC system. The membrane in the preparative-scale ion exchanger units is pleated, and was used with the HFS.

graphic (FPLC) system. For preparative-scale purification, 1400 and $2400 \mathrm{~cm}^{2}$ membrane ion exchanges were used (Fig. 1).

A special high-flux system (Fig. 2) was developed for optimum use of the preparative membrane ion exchanger units (MIEX $Q, S$ ). This system allows high flow-rates (up to 1200

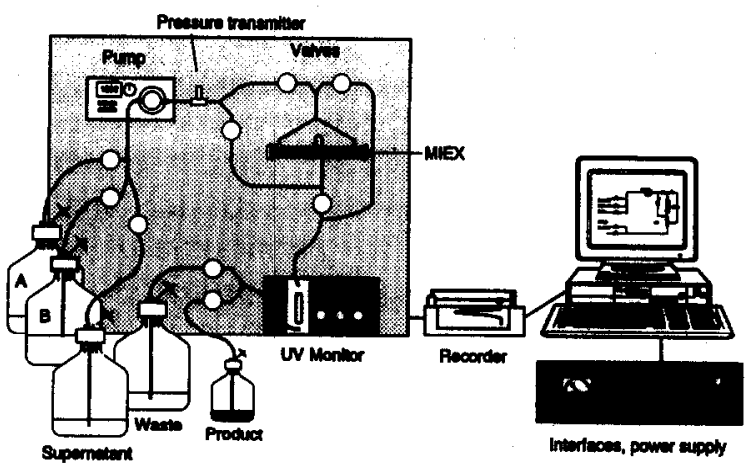

Fig. 2. High-flux system (HFS) consisting of a gear-wheel pump, a UV monitor, a pressure transmitter and special valves. A personal computer was equipped with interfaces for A/D, D/A and TTL signal transfer. Specially developed software offers the opportunity to control the valves and to monitor the UV and pressure signals, thus permitting complete automatisation. The system was developed for optimum use of the preparative membrane ion exchanger units and allows flow-rates up to $1200 \mathrm{ml} / \mathrm{min}$ and a maximum pressure of 1.2 bar. $\mathrm{ml} / \mathrm{min}$ ) and a change in flow direction, which is very important for reducing the elution volume and also helps to prevent fouling of the membrane. Corresponding controlling software, allowing complete automation of the whole process, has been developed and is currently being tested.

Heparin, a highly sulphated surface mucopolysaccharide $\left(M_{\mathrm{r}} 5000-30000\right)$ shows affinity interactions with many enzymes [6], namely enzymes of the nucleic acid metabolism [6], lowand high-density lipoproteins [7], lysosomal hydrolases [6] and many factors of the blood coagulation cascade [8]. In our case we exploit the particularly high affinity interaction that exists between heparin and ATIII [9] by covalently coupling the former to a membrane. The method of reductive amination [10] was chosen because of its reported ability to couple heparin in an oriented and stable manner [11].

\section{EXPERIMENTAL}

\section{Cell culture}

Cells. A rat/mouse hybridoma (HB 58; ATCC) and a mouse/mouse hybridoma were cultivated. Both cell lines secreted monoclonal antibodies type $\operatorname{IgG}_{1}$ with an isoelectric point $\mathrm{p} I \geqslant 7$. The recombinant Chinese hamster ovary (rCHO) cell line produced human active recombinant antithrombin III (rATIII) [12], a glycoprotein which is an important regulator of blood coagulation.

Medium. A serum-free standard medium [13] containing human transferrin $(10 \mathrm{mg} / \mathrm{l})$, bovine insulin $(10 \mathrm{mg} / \mathrm{l})$ and bovine albumin $(1 \mathrm{~g} / \mathrm{l})$ complexed with oleic acid as the main protein components was used. A lipoprotein fraction (Excyte I; Bayer Diagnostic, Munich, Germany) was added $(1 \mathrm{ml} / 1)$. On the $100-1$ scale and for the cultivation of the $\mathrm{CHO}$ cell line, albumin was omitted.

Bioreactors. The cell lines were cultivated in a 2-1 bench-scale perfusion system (Biostat BF 2) and in a 100-1 bioreactor (Biostat $100 \mathrm{~L}$ ) (Braun Biotech International, Melsungen, Germany). $\mathrm{pO}_{2}$ was set at $40 \%$ air saturation, $\mathrm{pH}$ at 7.1 , stirrer speed at $30 \mathrm{rpm}$ and temperature at $37^{\circ} \mathrm{C}$. 
Membrane ion exchangers

The studies were performend with Sartobind membrane ion exchangers, which were kindly supplied by Sartorius (Göttingen, Germany). A characterization of the membranes is given in Table I.

The high-flux system (HFS) (Fig. 2) consists of a gear-wheel pump (Watson Marlow $5003 \mathrm{U}$ ), a UV monitor (Uvicord; Pharmacia, Uppsala, Sweden), a pressure transmitter (Kistler Instruments, Winterthur, Switzerland) and special valves (Type 700; Bürkert, Ingelfingen, Germany). A personal computer was equipped with interfaces for $A / D, D / A$ and TTL signal transfer. Specially developed software offering the opportunity to control the valves and to monitor the UV and pressure signals, thus allowing complete automation, has been developed and is currently being tested. The system was developed for optimum use of the preparative membrane ion exchanger units and allows flow-rates up to 1200 $\mathrm{ml} / \mathrm{min}$ and a maximum pressure of 1.2 bar. In order to reduce the elution volume and to prevent fouling, the flow direction was changed between loading and the other steps (Fig. 3).

Sample preparation. In order to bind proteins to the ion exchanger, the conductivity of the

\section{TABLE I}

CHARACTERISTICS OF THE SARTOBIND MEMBRANES S, Q AND A

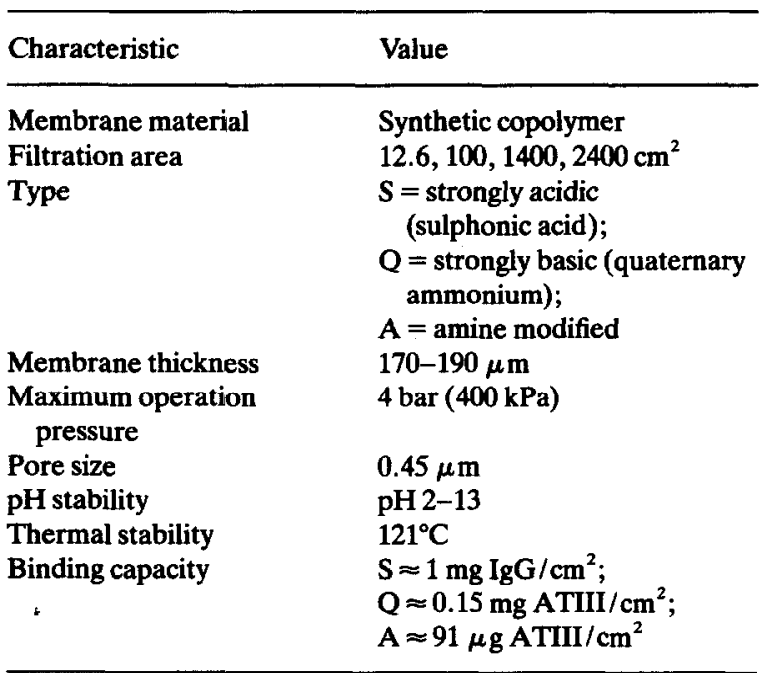
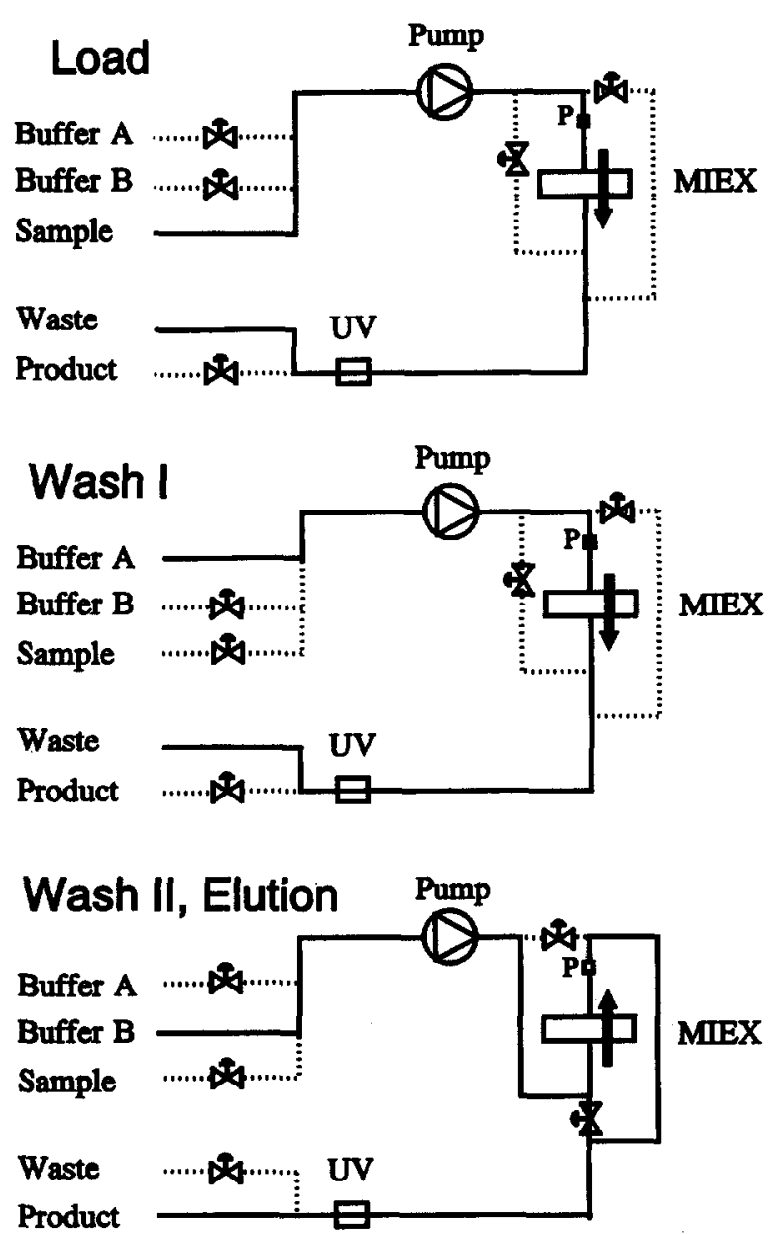

Fig. 3. Process diagram of the HFS. Load: the sample is filtered through the membrane. Wash I: the membrane is washed with buffer $A$ to remove unbound proteins. Wash II: a change in the flow direction (back-flush) of buffer $A$ is used to prevent fouling of the membrane. Elution: buffer $B$ eluates the bound protein.

supernatant had to be reduced from $13 \mathrm{mS} / \mathrm{cm}$ (normal cell culture medium) to $1.3-1.8 \mathrm{mS} / \mathrm{cm}$. In addition, some of the supernatants were first concentrated by ultrafiltration. To achieve this reduction in conductivity, several methods were used, including a diafiltration cross-flow system (S10Y30, SP20; Amicon, Beverly, MA, USA), an electrodialysis system (StanTech, Geesthacht, Germany) and simple dilution with water (Fig. 4). After adjusting the $\mathrm{pH}$ to 5.8 for MAbs and pH 7 for rATIII, the supernatant was passed through the S- and Q-type membrane ion ex- 
General production scheme:

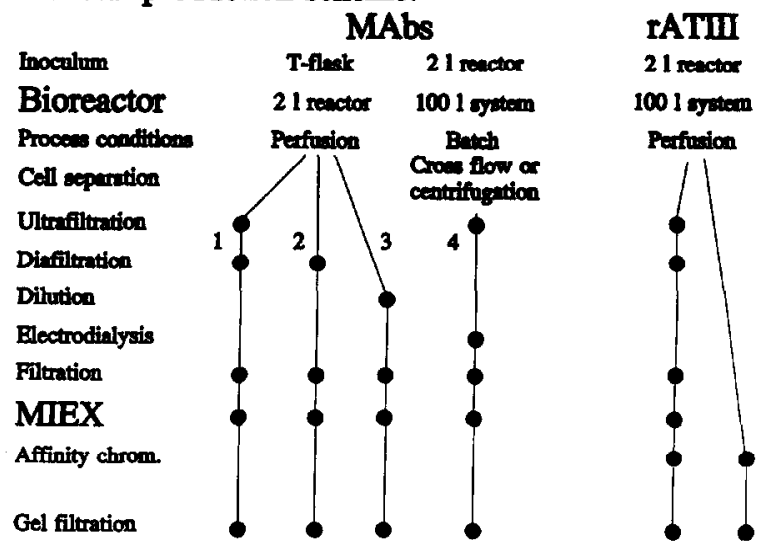

Fig. 4. Schematic diagram of the general processes used in the production and purification of MAbs and rATIII. The different sample preparation steps for the membrane ionexchange chromatography are presented together with the purification process employing the amine-modified affinity membranes.

changers, respectively, using the HFS or FPLC system. The product was eluted from the membrane by changing the salt concentration.

Buffers. For the acidic ion exchanger, buffer system I was (A) $25 \mathrm{mM}$ 2-(N-morpholino)ethanesulphonic acid) (MES)-10 $\mathrm{mM}$ $\mathrm{NaCl}$ (pH 5.8) and (B) $25 \mathrm{mM}$ MES-250 $\mathrm{mM}$ $\mathrm{NaCl}$ (pH 5.8); buffer system II was (A) $10 \mathrm{mM}$ sodium-phosphate-10 $\mathrm{mM} \mathrm{NaCl} \mathrm{p(H} \mathrm{5.8)} \mathrm{and}$ (B) $10 \mathrm{mM}$ sodium-phosphate-250 $\mathrm{mM} \mathrm{NaCl}$ pH 5.8. For the basic ion exchanger, the buffer system was (A) $20 \mathrm{mM}$ Tris- $\mathrm{HCl}(\mathrm{pH} 7)$ and (B) $20 \mathrm{mM}$ Tris- $\mathrm{HCl}-250 \mathrm{mM} \mathrm{NaCl}(\mathrm{pH} 7)$.

Cleaning and regeneration. Using $0.2 M$ $\mathrm{NaOH}\left(60^{\circ} \mathrm{C}, 20 \mathrm{~min}\right)$, the membranes could be cleaned without loss of binding capacity [14] and were regenerated by washing with buffer $A$.

\section{Heparin affinity membranes}

Material. An LC system (Pharmacia Biosystems) consisting of a fraction collector, a UV monitor, a recorder and a peristaltic pump was used for these studies. The matrix was epoxy- or amine-modified synthetic copolymer membranes (Sartobind; Sartorius).

Coupling procedure with amine-modified membrane. The amine-modified membrane, a single sheet $4.7 \mathrm{~cm}$ in diameter, was washed thoroughly with $0.2 \mathrm{M}$ phosphate buffer ( $\mathrm{pH} 7.2$ ), placed in a sealed test-tube containing $20 \mathrm{mg}$ of heparin (sodium salt, from porcine intestinal mucosa, 180 USP units/mg; Sigma, St. Louis, MO, USA) and $15 \mathrm{mg}$ of sodium cyanoborohydride $\left(\mathrm{NaCNBH}_{3}\right)$ (Fluka, Buchs, Switzerland) in $5 \mathrm{ml}$ of $0.2 \mathrm{M}$ phosphate buffer ( $\mathrm{pH} \mathrm{7.2)}$ and then allowed to mix end-over-end for 8 days at room temperature. Completion of the coupling was determined by analysing the heparin content of the coupling solution by the method of Dubois et al. [15].

The remaining $\mathrm{NH}_{2}$ groups were acetylated according to Baues and Gray [16] with $10 \mathrm{ml}$ of acetic anhydride and $20 \mathrm{ml}$ of $0.2 \mathrm{M}$ sodium acetate, starting at $-20^{\circ} \mathrm{C}$ and mixed end-overend for $60 \mathrm{~min}$ at room temperature. After thorough washing in buffer $A$ the membrane was placed in a membrane holder (Sartorius), which reduced the effective surface area of the membrane to $12.56 \mathrm{~cm}^{2}$, and equilibrated with $200 \mathrm{ml}$ of buffer A for the first run.

Coupling procedure with epoxy-modified membrane. The $100 \mathrm{~cm}^{2}$ epoxy-modified membrane module was placed in a coupling array consisting of a peristaltic pump and a reservoir allowing the respective solutions to be circulated through the membrane. The membrane was washed with 300 ml of $0.2 M$ phosphate buffer (pH 7.2) (without circulation) and then treated for 3 days with 200 $\mathrm{ml}$ of $0.2 M$ ethylendiamine (EDA), with the $\mathrm{pH}$ adjusted to 8.5 in order to prevent damage to the casing of the module. The membrane was then washed one way with $500 \mathrm{ml}$ of $0.2 \mathrm{M}$ phosphate buffer ( $\mathrm{pH}$ 7.2). The coupling solution, consisting of $30 \mathrm{mg}$ of heparin (sodium salt, from ovine intestinal mucosa, $182 \mathrm{IU} / \mathrm{mg}$; Sigma) and $30 \mathrm{mg}$ of $\mathrm{NaCNBH}_{3}$ in $9 \mathrm{ml}$ of $0.2 \mathrm{M}$ phosphate buffer (pH 7.2) was circulated over the membrane for 5 days. After 3 days an additional $50 \mathrm{mg}$ of $\mathrm{NaCNBH}_{3}$ in $1 \mathrm{ml}$ of $0.2 M$ phosphate buffer (pH 7.2) were added. The remaining $\mathbf{N H}_{2}$ groups were again removed by acetylation.

Sample run. A typical sample run consisted of equilibration with $100 \mathrm{ml}$ of buffer $A(10 \mathrm{ml} /$ min) followed by loading of the membrane with supernatant, $\mathrm{pH}$ adjustment to $5.8(1-10 \mathrm{ml} /$ $\mathrm{min}$ ), a wash step with $100 \mathrm{ml}$ of buffer $A$ and finally elution with buffer $B$ (both $10 \mathrm{ml} / \mathrm{min}$ ). 
Buffers. The buffers were (A) $20 \mathrm{~m} M$ 4-(2hydroxyethyl)-1-piperazineethanesulphonic acid (HEPES)-150 $\mathrm{mM} \mathrm{NaCl}(\mathrm{pH} \mathrm{5.8)}$ and (B) 20 $\mathrm{m} M$ HEPES-2.5 $M \mathrm{NaCl}$ (pH 7).

Cleaning. In order to prevent fouling of the membrane equilibration, washing and elution were always performed in a different flow direction to loading, resulting in backflushing of the system. Additional cleaning of the membrane with $2.5 \%$ sodium dodecyl sulphate (SDS) solution was also successful and resulted in removal of clogging material from the membrane, so that the original flow-rates were restored.

Final purification. This was carried out using a preparative gel filtration column (Superdex 200 PG; Pharmacia) with a $600-\mathrm{ml}$ gel volume. A 20 $\mathrm{m} M$ phosphate buffer containing $150 \mathrm{mM} \mathrm{NaCl}$ was used. The flow-rate was set at $6 \mathrm{ml} / \mathrm{min}$.

\section{Analytical methods}

Antibody concentrations were determined using a standard kinetic sandwich enzyme-linked immunosorbent assay (ELISA) method or an ABICAP affinity column (Abion, Jülich, Germany) for rapid analysis. rATIII concentrations were also determind by kinetic ELISA (Behring Werke, Marburg, Germany). Purity was determined by SDS-polyacrylamide gel electrophoresis (PAGE) [17] either automatically (Phast System; Pharmacia) using silver staining [18] or manually (Multiphor II; Pharmacia) using Sensi-quant Coomassie Brilliant Blue staining [19]. The silver-stained gels were scanned using the Gel-Image 1DEVA software (Pharmacia).

The concentration of heparin in the coupling solution was determined using the phenol-based method described by Dubois et al. [15].

Conversion factor. In order to compare membraneous and gel matrices with respect to ligands and protein bound, a conversion factor, obtained from Sartorius [20], equalling $50 \mathrm{~cm}^{2}$ of membrane surface with $1 \mathrm{ml}$ of gel matrix was used. It is also important to note that the $17.35-\mathrm{cm}^{2}$ membrane was placed in a filter holder that reduced the effective surface area to $12.56 \mathrm{~cm}^{2}$. All calculations made refer to these values unless stated otherwise.

\section{RESULTS AND DISCUSSION}

\section{Purification of MAbs with membrane ion} exchangers $100-\mathrm{cm}^{2}$ membrane ion exchanger

In order to find the optimum conditions for protein binding to the membrane ion exchanger, supernatant feed solutions of various $\mathrm{pH}$ and ionic strength were applied to a $100-\mathrm{cm}^{2}$ module (Fig. 5). It was found that a pH of 5.8 and a corresponding ionic strength of $1.8 \mathrm{mS} / \mathrm{cm}^{2}$ yielded the best results ( $96 \%$ recovery). During the runs conducted so far over $50 \mathrm{mg}$ of IgG per module could be bound employing a maximum flow-rate of $30 \mathrm{ml} / \mathrm{min}$. The concentration factor was about 50 -fold, which is comparable to that of other ion-exchange matrices. Most of the albumin could be separated by gradient elution; human transferrin, however, was concentrated under the conditions stated above (Fig. 6).

\section{Preparative purification of MAbs using the HFS}

The capacity of the membrane ion exchanger of $1 \mathrm{mg} \mathrm{IgG} / \mathrm{cm}^{2}$ (equivalent to $50 \mathrm{mg} \mathrm{IgG/ml}$ bed volume), as determined with a single filter

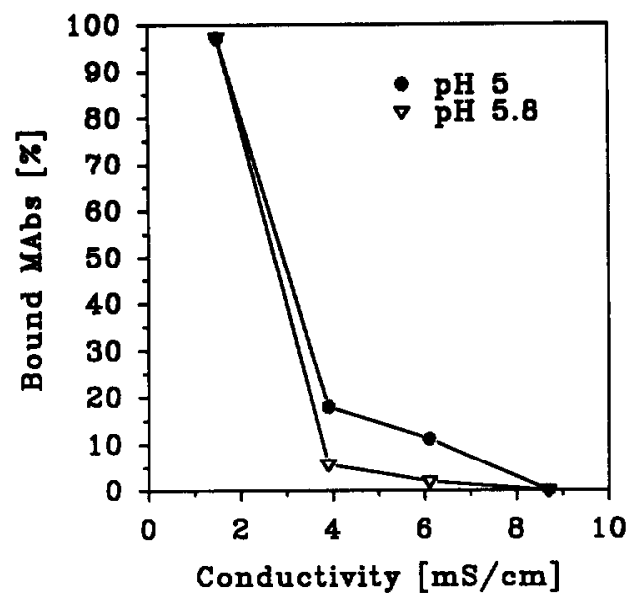

Fig. 5. Relationship between conductivity of the supernatant and binding of MAbs using the $100-\mathrm{cm}^{2}$ membrane ion exchanger with a flow-rate of $10 \mathrm{ml} / \mathrm{min}$. In each run $7 \mathrm{mg}$ of MAbs were applied to the membrane. In order to bind more than $90 \%$ it was necessary to reduce the conductivity to values below $1.8 \mathrm{mS} / \mathrm{cm}$. Buffer systems: $0=\mathrm{pH} 5,25 \mathrm{mM}$ acetic acid-10 $\mathrm{mM} \mathrm{NaCl} ; \nabla=$ pH 5.8, $25 \mathrm{mM}$ MES-10 $\mathrm{mM}$ $\mathrm{NaCl}$; the $\mathrm{MAbs}$ were eluted with the corresponding buffer with $250 \mathrm{~m} M \mathrm{NaCl}$. 


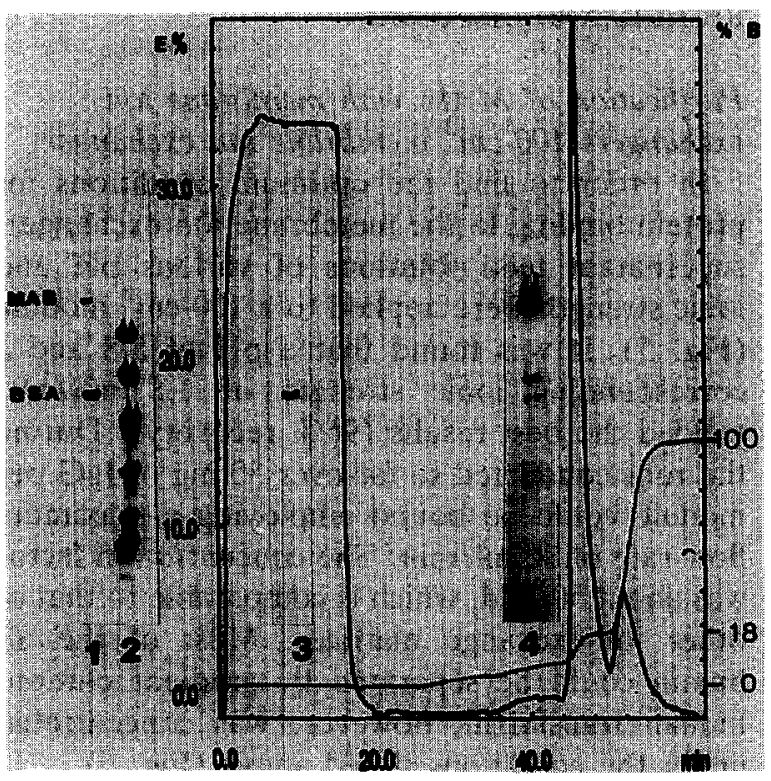

Fig. 6. Purification of monoclonal antibodies from cell culture supernatant. Following the diafiltration step the supernatant ( $9 \mathrm{mg}$ of MAbs) was applied to the membrane ion exchanger at a flow-rate of $6 \mathrm{ml} / \mathrm{min}$ [buffer system I, MES (pH 5.8)]. The binding rate was $95 \%$. Using a gradient from 0 to $8 \% \mathrm{~B}$ for $20 \mathrm{~min}$, impurities were separated. With an $18 \%$ step of buffer B, $90 \%$ of the MAbs could be eluted. The membrane was flushed with $100 \% \mathrm{~B}$ and washed with buffer A. SDS-PAGE (unreduced) shows the purification process. Samples were diluted 1:1 with buffer. Lanes: $1=$ crude cell culture supernatant $(150 \mathrm{ml}) ; 2$ = low-molecular-mass marker (reduced); 3 = breakthrough $(180 \mathrm{ml}) ; 4=$ MAbs eluted with $18 \% \mathrm{~B}(23 \mathrm{ml})$; the last peak contains unknown components but no proteins.

sheet $\left(12.56 \mathrm{~cm}^{2}\right.$ effective surface), is very high compared with filter materials from other suppliers. The preparative units could bind up to $910 \mathrm{mg}$ without any decrease in recovery (larger amounts were not determined). Lowering the ionic strength of the supernatant by method I, II or IV (Fig. 4) resulted in binding rates of about 95\% and recovery rates in excess of $80 \%$ (Table II). The recovery was found to be independent of the concentration of the supernatant. The only exception occurs if the relationship between the concentration of the MAbs and the volume in which they are dissolved becomes too unfavourable. A decrease in the ionic strength by simple 1:8 dilution with water (III) resulted in lower binding capacities if the feed solution exceeded a certain volume $(>61)$, but in this

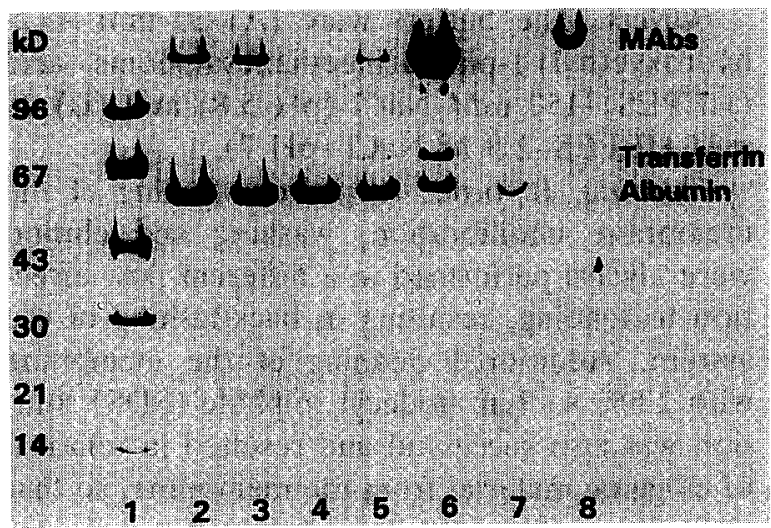

Fig. 7. SDS-polyacrylamide gradient gel (8-25\%) using a modified silver stain under unreduced conditions. Isolation of MAbs with strongly acidic membrane ion exchanger and gel filtration. Lanes: $1=$ marker, $M_{\mathrm{r}}$ 14000-96000 (reduced); 2 = supernatant; $3=$ supernatant after salt reduction; $4=$ unbound proteins (MIEX); 5= first wash (MIEX); 6= concentrated IgG (MIEX); $7=$ gel filtration 1 peak; $8=$ gel filtration 2 peak, purified MAbs. $\mathrm{kD}=$ kilodalton.

instance no expensive membrane step such as diafiltration was necessary. The concentration factor achieved by the MIEX is still unsatisfactory in comparison with a common ion exchanger (Table III), but optimization of the ion exchanger unit towards smaller elution volumes could change that. Up to a flow-rate of 571 $1 / \mathrm{m}^{2} \cdot \mathrm{h}$ (maximum achieved by the system) the binding of the MAbs on the MIEX was better than $90 \%$. The concentration of $5 \mathrm{~g}$ of IgG in several cycles with one unit was possible; sub-

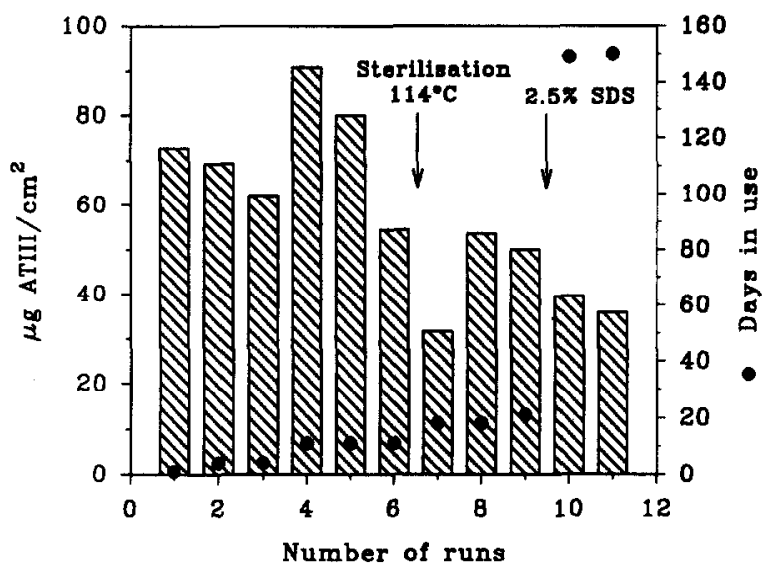

Fig. 8. Repeated use of the amine-modified membrane over a period of 150 days. Effects of steam sterilization and treatment with $2.5 \%$ SDS 
TABLE II

SUMMARY OF DIFFERENT SAMPLE PREPARATION STEPS AND THE SUBSEQUENT MEMBRANE IONEXCHANGER RUNS

Within minutes gram amounts of product could be purified in the HFS [buffer system I, sodium phosphate (pH 5.8)]. The concentration factor was calculated by dividing the IgG concentration in the elution by the IgG concentration in the supernatant. The recovery was found to be independent of the concentration of the supernatant. Lowering the ionic strength of the supernatant by method I, II or IV resulted in binding rates of about $95 \%$ and recoveries in excess of $80 \%$.

\begin{tabular}{lcccccccccc}
\hline Method & No. & $\begin{array}{l}\text { IgG } \\
(\mathrm{mg})\end{array}$ & $\begin{array}{l}\text { Volume } \\
(\mathrm{ml})\end{array}$ & $\begin{array}{l}\text { IgG } \\
\text { bound } \\
(\%)\end{array}$ & $\begin{array}{l}\text { Flow- } \\
\text { rate } \\
(\mathrm{ml} / \mathrm{min})\end{array}$ & $\begin{array}{l}\text { Recovery } \\
(\%)\end{array}$ & $\begin{array}{l}\text { Concen- } \\
\text { tration } \\
\text { factor }\end{array}$ & $\begin{array}{l}\text { Process } \\
\text { time } \\
(\mathrm{h})\end{array}$ & $\begin{array}{l}\text { Throughput } \\
(\mathrm{g} / \mathrm{h})\end{array}$ & $\begin{array}{l}\text { IgG } \\
\text { species }\end{array}$ \\
\hline $\begin{array}{l}\text { (I) Ultrafiltration and } \\
\text { diafiltration }\end{array}$ & 1 & 320 & 2010 & 99 & 750 & 81 & 13.6 & 0.08 & 4.0 & Rat \\
& 2 & 187 & 5200 & 95 & 866 & 93 & 10.7 & 0.14 & 1.3 & Mouse \\
& 3 & 319 & 5500 & 99 & 845 & 81 & 12.7 & 0.15 & 2.1 & Mouse \\
& 4 & 910 & 1000 & 97 & 843 & 84 & 1.8 & 0.06 & 14.3 & Mouse \\
& 5 & 910 & 1000 & 99 & 843 & 94 & 2.6 & 0.06 & 14.3 & Mouse \\
(II) Diafiltration only & 6 & 187 & 5200 & 95 & 866 & 93 & 10.7 & 0.14 & 1.3 & Mouse \\
& 7 & 166 & 4600 & 99 & 836 & 96 & 14.3 & 0.13 & 1.3 & Mouse \\
& 8 & 43 & 3300 & 95 & 843 & 81 & 8.9 & 0.11 & 0.4 & Mouse \\
(III) Dilution of the & 9 & 146 & 3500 & 91 & 845 & 91 & 10.3 & 0.11 & 1.3 & Mouse \\
supernatant with & 10 & 139 & 5600 & 94 & 345 & 91 & 17.7 & 0.15 & 0.9 & Mouse \\
water & 11 & 37 & 16700 & 73 & 843 & 68 & 17.2 & 0.37 & 0.1 & Rat \\
& 12 & 110 & 14300 & 68 & 843 & 66 & 22.1 & 0.32 & 0.3 & Rat \\
& 13 & 240 & 34500 & 63 & 843 & 57 & 122 & 0.72 & 0.3 & Rat \\
(IV) Ultrafiltration and & 14 & 456 & 1400 & 91 & 845 & 90 & 3.1 & 0.11 & 4.2 & Mouse \\
electrodialysis & 15 & 489 & 1500 & 91 & 845 & 84 & 4.0 & 0.11 & 4.3 & Mouse \\
& 16 & 391 & 1200 & 98 & 845 & 75 & 3.0 & 0.11 & 3.6 & Mouse \\
& 17 & 267 & 1100 & 97 & 1060 & 80 & 4.4 & 0.08 & 3.3 & Mouse \\
\hline
\end{tabular}

TABLE III

COMPARISON BETWEEN A GEL-MATRIX CATION EXCHANGER (S-SEPHAROSE FF) AND THE STRONGLY ACIDIC MEMBRANE ION EXCHANGER (SARTOBIND S)

\begin{tabular}{lll}
\hline Parameter & Matrix & \\
\cline { 2 - 3 } & S-Sepharose FF & Sartobind S \\
\hline Bed volume/area & $28 \mathrm{ml}$ & $1400 \mathrm{~cm}^{2}$ \\
& $(X K 50 \times 30)^{a}$ & \\
Supernatant volume (ml) & 4700 & 5500 \\
Flow-rate (ml/min) & 80 & 845 \\
MAbs applied (mg) & 359 & 319 \\
MAbs bound (\%) & 69 & 99 \\
Recovery (\%) & 67 & 81 \\
Concentration factor & 58 & 13 \\
Process time (h) & 1.50 & 0.15 \\
Throughput (g/h) & 0.16 & 2.10 \\
\hline
\end{tabular}

${ }^{a}$ Pharmacia, S. sequently a treatment with $0.2 \mathrm{M} \mathrm{NaOH}\left(60^{\circ} \mathrm{C}\right.$, $20 \mathrm{~min}$ ) restored the flow. So far one MIEX unit has been used 25 times without decreases in binding capacity, recovery or flow-rate. The main advantage of the MIEX in comparison with an ion exchanger based on gel matrices is the much higher throughput (>13-fold) (Table III). Final purification of the MAbs was carried out using a preparative gel filtration column. The elutions from the MIEX were applied directly, without prior concentration, to the gel filtration column and resulted in two distinct peaks. The second peak contained the purified MAbs (Fig. 7).

\section{Purification of rATIII}

Affinity membranes. The $17.35-\mathrm{cm}^{2}$ aminemodified membrane covalently coupled $5.2 \mathrm{mg}$ of heparin (porcine), corresponding to $\mathrm{ca} .0 .3$ $\mathrm{mg}$ heparin $/ \mathrm{cm}^{2}$ matrix, which is slightly higher 
than that obtained by Sasaki et al. $\left(0.2 \mathrm{mg} / \mathrm{cm}^{2}\right)$ [11]. The coupling took fairly long to complete ( 8 days), but this is not uncommon for reductive amination $[10,21]$ and the optimized conditions that were taken from the paper by Sasaki $e t$ al. [11], which were obtained using amino-Sepharose as a matrix, might not apply completely to the membraneous matrix used in this instance. The maximum amount of rATIII that could be adsorbed to the amine-modified membrane was $1.14 \mathrm{mg}$ (Fig. 8), which amounts to a binding capacity of $90.8 \mu \mathrm{g} / \mathrm{cm}^{2}$ (effective surface area $12.56 \mathrm{~cm}^{2}$ ). This value equals or exceeds that of other commercially available heparin affinity matrices. The stability achieved by the method of reductive amination used in this instance was very satisfactory especially when compared with the known shortcomings [10] of products coupled by the cyanogen bromide method. The aminebased heparin-affinity membrane was used eleven times over a period of about 5 months, purifying a total of $8.2 \mathrm{mg}$ of rATIII. It was also sterilized by steam sterilization $\left(15 \mathrm{~min}\right.$ at $\left.114^{\circ} \mathrm{C}\right)$ after six runs, losing about $38 \%$ of its capacity (average of the first six runs, $71.7 \mu \mathrm{g}$ rATIII/ $\mathrm{cm}^{2}$; average of the last five runs, $43.9 \mu \mathrm{g} / \mathrm{cm}^{2}$ ) and treated sucessfully at one time with $2.5 \%$ SDS solution to remove clogging material from the membrane surface.

The $100-\mathrm{cm}^{2}$ module containing an epoxyactivated membranc, which was first treated with ethylenediamine in order to produce sufficient spacers, coupled $12 \mathrm{mg}$ of heparin (ovine) in 5 days, which corresponds to $0.18 \mathrm{mg}$ heparin/ $\mathrm{cm}^{2}$. The best run resulted in the purification of $3.95 \mathrm{mg}$ of rATIII, which denotes a binding capacity of $39.5 \mu \mathrm{g} / \mathrm{cm}^{2}$. The $100-\mathrm{cm}^{2}$ module purified a total of $18 \mathrm{mg}$ of rATIII in eight runs over a period of almost 3 months (Fig. 9). The $100-\mathrm{cm}^{2}$ module lost considerable binding capacity (about $65 \%$ when comparing the average of the first three runs with that of the last five) (Fig. 9). This loss might be due to storing the filter without first removing the clogging material. Treatment with $2.5 \%$ SDS after the fifth run, however, resulted in an improvement of the rATIII binding capacity (Fig. 9).

The initial purity of the eluates was about $75 \%$

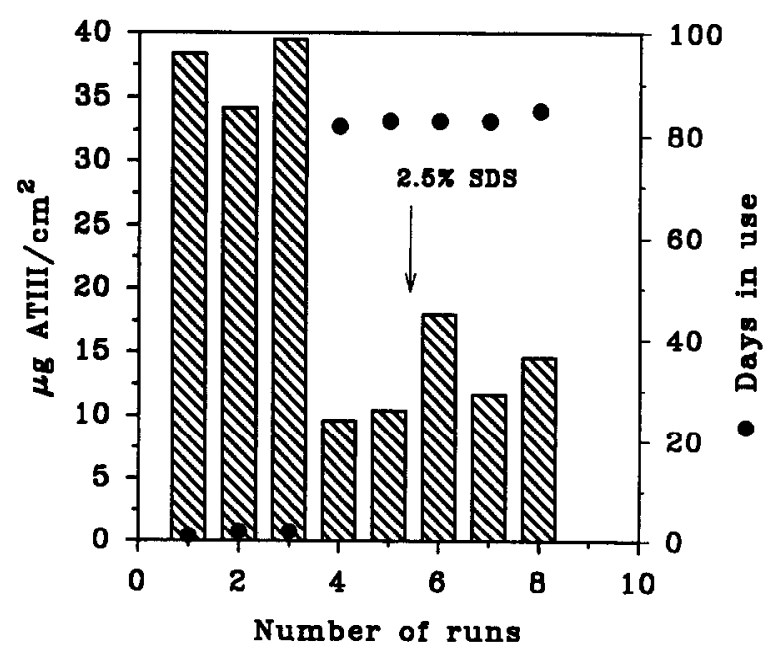

Fig. 9. Repeated use of the epoxy-modified membrane over a period of 85 days. Effect of treatment the membrane with $2.5 \%$ SDS.

(as determined with the Gel-Image system), with impurities mainly in the lower-molecular-mass range. These non-specific bindings might be due to the many affinity interactions of heparin [6], or the fact that heparin as a highly sulphated saccharide polyanion has some of the properties of a cation exchanger. The low-molecular-mass protein impurities were readily removed by gel filtration (Fig. 10).

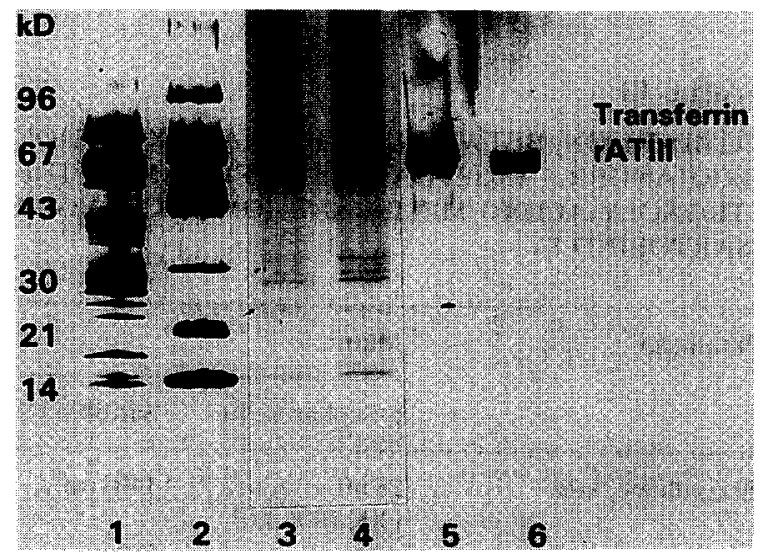

Fig. 10. SDS polyacrylamide gradient gel (8-25\%) using a modified silver stain under unreduced conditions. Isolation of rATIII with basic preparative ion exchanger, amine-modified affinity membranes and gel filtration. Lanes: $1=$ supernatant after ultra- and diafiltration (concentrated tenfold); $2=$ marker, $M_{\mathrm{r}} 14000-96000$ (reduced); $3+4=$ elution of rATIII from MIEX $Q ; 5=$ elution of rATIII from affinity membrane; $6=$ pure rATIII (after affinity membrane and subsequent gel filtration.) 
TABLE IV

CONCENTRATION OF IATII WITH THE STRONGLY BASIC MEMBRANE ION EXCHANGER $\left(2400 \mathrm{~cm}^{2}\right)$ USING THE HFS

\begin{tabular}{lllllllll}
\hline No. & $\begin{array}{l}\text { rATIII } \\
(\mathrm{mg})\end{array}$ & $\begin{array}{l}\text { Volume } \\
(\mathrm{ml})\end{array}$ & $\begin{array}{l}\text { rATIII } \\
\text { bound } \\
(\%)\end{array}$ & $\begin{array}{l}\text { Flow-rate } \\
(\mathrm{ml} / \mathrm{min})\end{array}$ & $\begin{array}{l}\text { Recovery } \\
(\%)\end{array}$ & $\begin{array}{l}\text { Concentration } \\
\text { factor }\end{array}$ & $\begin{array}{l}\text { Process } \\
\text { time } \\
(\mathrm{h})\end{array}$ & $\begin{array}{l}\text { Throughput } \\
(\mathrm{g} / \mathrm{h})\end{array}$ \\
\hline 1 & 210 & 2000 & 100 & 560 & 99 & 3.9 & 0.08 & 2.6 \\
2 & 240 & 2000 & 100 & 560 & 99 & 2.5 & 0.15 & 1.5 \\
3 & 140 & 550 & 98 & 380 & 98 & 1.6 & 0.51 & 0.3 \\
4 & 344 & 7500 & 100 & 580 & 96 & 14.4 & 0.51 & 0.6 \\
5 & 366 & 8000 & 100 & 600 & 79 & 11.8 & 0.47 & 0.8 \\
6 & 113 & 5000 & 93 & 610 & 79 & 13.1 & 0.31 & 0.5 \\
7 & 110 & 3500 & 85 & 620 & 82 & 11.9 & 0.22 & 0.5 \\
8 & 68 & 4500 & 100 & 620 & 98 & 22.0 & 0.28 & 0.3 \\
9 & 18 & 3500 & 100 & 620 & 92 & 17.8 & 0.36 & 0.05 \\
\hline
\end{tabular}

The affinity of the heparin membranes towards human transferrin, the most critical contaminant in this instance, is very weak. Ionic interactions with the matrix were further diminished by adjusting the $\mathrm{pH}$ of the supernatant to 5.8 , the isoelectric point of human transferrin.

Preparative purification of rATIII using the $H F S$. The $2400-\mathrm{cm}^{2}$ units could be run with flow-rates up to $620 \mathrm{ml} / \mathrm{min}$, achieving binding rates of $97 \%$ and recoveries of about $91 \%$ (Table

\section{TABLE V}

COMPARISON OF A GEL-MATRIX ANION EXCHANGER (Q-SEPHAROSE FF) AND THE STRONGLY BASIC MEMBRANE ION EXCHANGER (SARTOBIND Q)

\begin{tabular}{lll}
\hline Parameter & Matrix & \\
\cline { 2 - 3 } & Q-Sepharose FF & Sartobind Q \\
\hline Bed volume/area & $30 \mathrm{ml}$ & $2400 \mathrm{~cm}^{2}$ \\
& $(\mathrm{XK} 50 \times 30)^{a}$ & \\
Supernatant volume (ml) & 4200 & 7500 \\
Flow-rate (ml/min) & 60 & 580 \\
rATIII applied (mg) & 246 & 344 \\
rATIII bound (\%) & 100 & 100 \\
Recovery (\%) & 95 & 96 \\
Concentration factor & 42 & 14 \\
Process time (h) & 1.70 & 0.51 \\
Throughput (g/h) & 0.15 & 0.60 \\
\hline
\end{tabular}

${ }^{a}$ Pharmacia, S.
IV). The estimated capacity of the anion exchanger membrane for rATIII of $0.15 \mathrm{mg} / \mathrm{cm}^{2}$ (360 mg/unit) is low compared with the capacity of the S type for MAbs; this might be due to the competive binding of DNA and other negatively charged biomolecules under these conditions. The purity of the product was $75 \%$, with human transferrin as one of the main impurities (Fig. 10). In comparison with standard ion exchangers (Table V), MIEX shows similar binding and recovery rates. Only the concentration factor (elution volume) could be improved in the future. Purification with MIEX resulted in a throughput more than four times higher than Q-Sepharose FF.

\section{CONCLUSIONS}

Membrane ion exchanger and affinity membranes are versatile tools for the concentration and purification of MAbs and rATIII. The binding capacity, the recovery and the concentration factor (only by the $100-\mathrm{cm}^{2}$ unit) are similar to those for gel matrices. The main advantage is the very high throughput. They are easy to handle and can be used repeatedly.

\section{ACKNOWLEDGEMENTS}

This work was supported in part by the project "Development of a procedure and a plant for the recirculation of nutrient media for animal cell 
culture" (BMFT ref. No. 0319346A) of the German Ministry of Research. We thank Sartorius (Göttingen, Germany) for prototypes of the membrane ion exchangers and affinity membranes and Behring Werke (Marburg, Germany) for kindly supplying the $\mathrm{CHO}$ cell line and the ATIII immunoassays. We thank Mr. H. Rengstorf for excellent technical assistance.

\section{REFERENCES}

1 P. Langlotz and K.H. Kroner, J. Chromatogr., 591 (1992) 107.

2 K.H. Kroner, S. Krause and W.D. Deckwer, $D E$ CHEMA Biotechnol. Conf., 5 (1992) 707.

3 B. Champluvier, G. Briefs and M.R. Kula, in C. Christiansen, L. Munck and J. Villadsen (Editors), 5th ECB, Copenhagen, July 1990, Vol. 1, Munsksgaard, Copenhagen, 1990 , p. 525.

4 K.-G. Briefs and M.-R. Kula, DECHEMA Biotechnol. Conf., 4 (1990) 225.

5 K.H. Kroner, S. Krause and W.D. Deckwer, presented at Engineering Foundation Conference, Recovery of Biological Products VI, Interlaken, Switzerland, 1992.

6 A. Farooqui, J. Chromatogr., 184 (1980) 335.

7 T. Pan, A.W. Kruski and A.D. Elbein, Arch. Biochem. Biophys., 189 (1978) 231.
8 P.J. Marshall, Biotechnology, 11 (1989) 223 (7).

9 T.W. Barrowcliffe, E.A. Johnson, D. Thomas, Br. Med. Bull, 34, No. 2 (1978) 143.

10 R. Gray, Arch. Biochem. Biophys., 163 (1974) 426.

11 H. Sasaki, A. Kitagaki-Ogawa, I. Matsumoto and N. Seno, J. Chromatogr., 400 (1987) 123.

12 G. Zettlmeissl, H. Ragg and H. Karges, Biotechnology, 5 (1987) 720.

13 H. Büntemeyer, D. Lütkemeyer and J. Lehmann, Cytotechnology, 5 (1991) 57.

14 D. Lütkemeyer, S. Siwiora, H. Büntemeyer and J. Lehmann, Bio Engineering, 2 (1992) 34.

15 M. Dubois, K.A. Gilles, J.K. Hamilton, P.A. Rebers and F. Smith, Anal. Chem., 28 (1956) 350.

16 R.J. Baues and G.R. Gray, J. Biol. Chem, 252 (1977) 57.

17 Laemmli, Nature, 227 (1970) 680.

18 J. Heukeshoven and R. Dernick, Electrophoresis, 9 (1988) 28-32.

19 J. Bülles, H. Barzik, R. J. Klosson, H. P. Schickle and S. Gronau, Pharmacia Application Paper, A 49 6/90, Pharmacia, Uppsala, 1990.

20 W. Demmer, H.H. Hörl, A.R. Weiss, E. Wünn and D. Nussbaumer, in C. Christiansen, L. Munck and J. Villadsen (Editors), 5th ECB, Copenhagen, July 1990, Vol. II, Munsksgaard, Copenhagen, 1990, p. 766.

21 I. Matsumoto, H. Kitagaki, Y. Akai, Y. Ito and N. Seno, Anal. Biochem., 116 (1981) 103. 